\title{
RACISMO ESTRUTURAL E SEUS REFLEXOS NAS CORPORAÇÕES: O PAPEL DAS POLÍTICAS DE COMPLIANCE NA LUTA ANTIRRACISTA E A NECESSÁRIA MUDANÇA CULTURAL
}

\section{Structural racism and its reflexes in corporations: the role of Compliance policies in the anti-racist struggle and the necessary cultural change}

Fernanda Ravazzano Lopes Baqueiro Universidade Católica de Salvador (UCSAL), Salvador, BA, Brasil

Silvia Monique Santos Cezar Universidade Católica de Salvador (UCSAL), Salvador, BA, Brasil

\section{Informações do artigo}

Recebido em 10/03/2021 Aceito em 07/05/2021

doi>: https://doi.org/10.25247/2447-861X.2021.n252.p166-192

Esta obra está licenciada com uma Licença Creative Commons Atribuição 4.0 Internacional.

\section{Como ser citado (modelo ABNT)}

BAQUEIRO, Fernanda Ravazzano Lopes; CEZAR, Silvia Monique Santos. Racismo estrutural e seus reflexos nas corporações: o papel das políticas de Compliance na luta antirracista e a necessária mudança cultural. Cadernos do CEAS: Revista Crítica de Humanidades. Salvador/Recife, v. 46, n. 252, p. 166-192, jan./abr. 2021. DOI: hhttps://doi.org/10.25247/2447-861X.2021.n252.p166-192

\begin{abstract}
Resumo
Trata-se de artigo que objetiva analisar a contribuição das políticas de compliance para a promoção da necessária mudança cultural no abandono das heranças seculares racistas que permeiam a sociedade brasileira. Com efeito, busca-se abordar, inicialmente, o racismo estrutural, na perspectiva histórica e como está enraizado e se espraia nas relações sociais até os dias atuais. Em seguida, analisa-se o que são as políticas de compliance, desde sua origem, perpassando pela compreensão de que os programas de conformidade não se limitam às questões econômicas da pessoa jurídica, mas a todas as relações por ela travadas, sobretudo com seus stakeholders, para, ao final, questionar em que medida o compliance pode ser importante ferramenta na luta antirracista e na promoção da justiça social. Para tanto foi empregado o método hermenêutico, com a releitura de obras e artigos científicos, nacionais e estrangeiros, com abordagem qualitativa.
\end{abstract}

Palavras-Chave: Racismo estrutural. Políticas de compliance. Mudança cultural.

\section{Abstract}

This is an article that aims to analyze the contribution of compliance policies to the promotion of the necessary cultural change in the abandonment of the racist secular inheritances that permeate Brazilian society. In effect, we seek to address, initially, structural racism, in the historical perspective and how it is rooted and spreads in social relations to the present day. Then, we will analyze what are the compliance policies, since their origin, going through the understanding that the compliance programs are not limited to the economic issues of the legal entity, but all the relations it engages, especially with its stakeholders, to, in the end, questioning the extent to which compliance can be an important tool in the anti-racist struggle and in the promotion of social justice. For this purpose, the hermeneutic method was used, with the re-reading of scientific and national works and articles, with a qualitative approach.

Keywords: Structural racism. Compliance policies. Cultural change.

\section{Introdução}

O presente artigo tem por finalidade abordar a importância das políticas de compliance $^{1}$ na luta antirracista.

\footnotetext{
${ }^{1}$ Do inglês, to comply, que consiste em "cumprir", ou seja, atuar em conformidade.
} 
Com efeito, as políticas de conformidade consistem no quarto pilar da governança corporativa (IBGC, 2017), exigindo a gestão da pessoa jurídica de forma responsável, buscando-se crescimento financeiro atrelado ao respeito e proteção aos stakeholders ${ }^{2}$. Dessa forma, tem-se os quatro princípios ou pilares da governança: prestação de contas (accountability), transparência (disclosure), equidade (fairness) e responsabilidade corporativa (compliance), interessando especificamente a esta pesquisa os programas de compliance.

Para tanto, em um primeiro momento será abordada a origem histórica do racismo no Brasil-sem pretender esgotar o assunto - a fim de verificar suas repercussões nas relações sociais atuais, trabalhando com as definições de racismo individual, institucional e estrutural.

Com efeito, a percepção do racismo estrutural e como ele se revela nas relações sociais, e, notadamente, seus impactos nas pessoas jurídicas, é essencial para a compreensão da importância dos programas de conformidade no combate ao racismo.

No tópico seguinte, será apresentado o conceito de compliance e suas premissas, bem como a importância da autorregulação regulada na necessária mudança cultural da sociedade e as repercussões na seara cível, administrativa e mesma criminal. O compliance officer será importante aliado na implementação e fiscalização de tais medidas, garantindo que todos os stakeholders (colaboradores) do ente moral compreendam que o atuar em conformidade significa não apenas a aderências às regras jurídicas, mas as regras morais, éticas e o respeito aos direitos fundamentais, como as práticas não discriminatórias.

No último item desta pesquisa abordaremos quais medidas especificamente podem ser adotadas por uma empresa para a luta antirracista e o principal questionamento que deve existir no momento da implementação dos programas de compliance é: qual a identidade que a pessoa jurídica deseja construir? Daí decorrem outras indagações: quais são seus valores, missão e visão? Qual a definição, para a alta administração do ente moral, da cidadania corporativa? Qual é a imagem que ela deseja passar para a sociedade? Como a autorregulação regulada pode contribuir para a necessária mudança cultural e abandono das raízes seculares racistas? Como, enfim, a justiça social pode ser feita?

\footnotetext{
2 Pessoas interessadas na empresa, quais sejam, todos os colaboradores da pessoa jurídica, como sócios, gestores, funcionários, parceiros, acionistas, investidores, entre outros.
} 
Para tentar responder a estas perguntas, será utilizado o método hermenêutico, buscando-se a interpretação crítica de conceitos e construções históricas, a partir da releitura de obras, artigos científicos nacionais e estrangeiros, com abordagem qualitativa, a fim de propor uma reflexão acerca da concepção sobre gestão empresarial.

\section{O racismo estrutural e seu reflexo nas corporações}

Antes de abordarmos o racismo dentro das corporações, insta rememorar as raízes históricas - sem pretender esgotar o assunto - do racismo na sociedade brasileira.

Com efeito, a pergunta "o que fazer com o negro?" permeia a obra "Onda negra medo branco" de Célia de Azevedo (1987), revelando, justamente, a grande preocupação da elite branca brasileira no final do século XIX e que se alastra até os dias atuais: o que fazer com o ex-escravo.

Libertado às pressas3 ${ }^{3}$ diante da necessidade do fomento do mercado capitalista - que já não mais permitia a escravidão, uma vez que o escravo não é capaz de consumir - e em razão da constatação do risco da população negra, a partir do momento em que tomar a consciência de seu poder, se rebelar, desafiando o controle da nação - como ocorrido na Revolução em São Domingos, havendo ainda movimentos sociais aqui no Brasil, especificamente na Bahia, através dos nagôs e haussás (AZEVEDO, 1987, p. 34-35) - os discursos edificados à época e que ecoam até os dias atuais foram pautados na consolidação do mito do homem negro perigoso.

Célia de Azevedo (1987) destaca, neste sentido, a participação crucial da imprensa, da academia e da elite branca em geral, na formação e fortalecimento da cultura do medo do negro. Desde a depreciação de seus traços físicos (cabelo crespo, lábios grossos, nariz largo) à criminalização de sua cultura (candomblé4 e outras práticas religiosas de matiz africana, música e luta) e das condutas que atentam contra o patrimônio (perpetradas por pobres para sobreviver, justamente formadas em sua maioria pelos ex-escravos, libertados sem qualquer

\footnotetext{
${ }^{3}$ Malgrado o Brasil tenha sido um dos últimos países do ocidente a aprovar o fim da escravidão na era moderna, através da simbólica "Lei Áurea" de 1888

4 O "estado de santo" foi estudado por Nina Rodrigues e por ele apontado como sintoma da doença psiquiátrica da histeria, como forma de menosprezar as crenças religiosas. (CORRÊA, 2001, p. 118)
} 
preocupação em fornecimento de emprego ou condições mínimas de vida), o discurso do medo foi criado, disseminado e fortalecido, prevalecendo até os dias atuais.

Embora a figura do homem negro perigoso não tenha surgido no Brasil, mas na Europa, as lições trazidas pela elite intelectual do velho continente foram apreciadas e utilizadas no país, para justificar o combate à raça indesejada.

Os naturalistas do século XIX esforçaram-se para construir teses científicas que traçassem diferenças hierárquicas entre as raças, e encontraram na teoria da recapitulação de Ernest Haeckel, zoólogo alemão, terreno fértil (GOULD, 1991).

A teoria da recapitulação, utilizando-se da teoria biológica criacionista, foi desenvolvida para explicar as diferenças embrionárias das formas superiores, expressando ainda Ernest Haeckel as diferenças dos estágios de desenvolvimento do homem durante sua vida, ou seja, que cada indivíduo possuiria sua "árvore da vida" (GOULD, 1991, p. 112); não obstante, com fulcro nesta teoria, outros estudiosos passaram a abordá-la para justificar a inferioridade da raça negra com relação à raça branca.

Além da teoria da recapitulação5, os estudos da craniometria foram exaustivamente utilizados para justificar a superioridade da raça branca. Por outro lado, os negros, por possuírem formato do crânio mais "próximo" dos ancestrais da raça humana, teriam a capacidade cognitiva comprometida, segundo os dizeres de Nott e Gidon:

5 Stephen Jay Gould (1991) aborda outras teorias biológicas utilizadas na Europa para tentar justificar a "superioridade" da raça branca sobre as demais e o gênero masculino sobre o feminino. 

Fig. 2.1. A escala unilinear das raças humanas e seus parentes inferiores, segundo
Nott e Gliddon, 1868 . O crânio do chimpanzé aparece incorretamente aumentado, e a mandíbula do negro falsamente distendida para dar a impressão de que os negros poderiam se situar até mesmo abaixo dos símios.

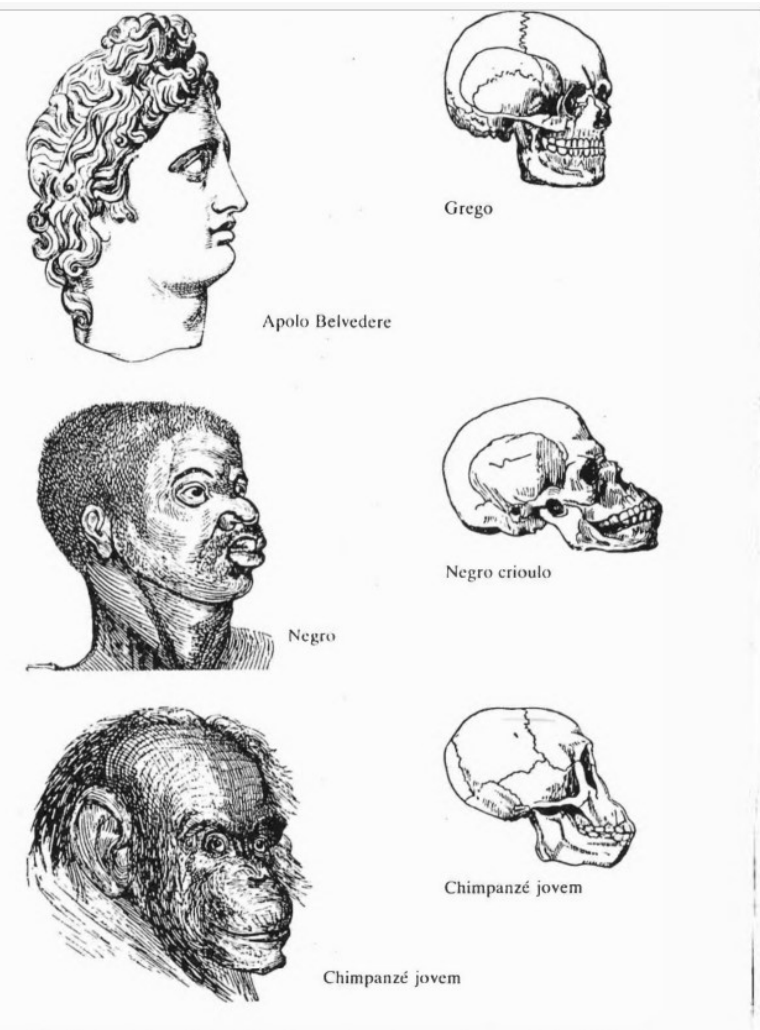

Fonte: (GOULD, 1991, p. 37).

Percebe-se, claramente, a real intenção na apresentação dos "dados científicos" (devidamente manipulados): apenas fundamentar a manutenção de um grupo racial no poder.

Mas a criminologia passa a ocupar papel essencial na propagação desse discurso, como percebemos nos ensinamentos de Cesare Lombroso na antropologia criminal, com a criação da figura do "homem delinquente", replicados no Brasil, sobretudo por Nina Rodrigues.

Nina Rodrigues em seu livro "As raças humanas e a responsabilidade penal no Brasil" apresenta as preocupações oriundas da raça negra e da mestiçagem. Pautado na antropologia criminal de Lombroso, sustenta a superioridade da raça branca e as vicissitudes do negro e o índio e os riscos de contaminação do caucasiano com a mescla com essas raças, formando os caboclos, pardos e cafusos, chegando a afirmar: "É verdade biológica bem 
conhecida que nos cruzamentos de espécies diferentes o êxito é tanto menos favorável quanto mais afastada na hierarquia zoológica estão entre si as espécies que se cruzam" (2011, p. 53). Dessa forma, as boas qualidades físicas e morais das raças originárias - notadamente, para ele, da raça caucasiana - degenerando o povo (2011, p. 56).

Esse "medo" da degeneração da raça branca é ainda reportado por Lilia Schwarz (1994, p. 137) e a própria negociação do conceito de raça. Como, então, nos portarmos diante de um país miscigenado? A miscigenação, tão odiada por degenerar a raça superior, levaria - Brasil a uma ruína? Como poderiam conviver brancos, negros, índios, asiáticos e mestiços? O caminho escolhido foi a separação das responsabilidades entre as diferentes raças e suas misturas, sempre no sentido de conferir a posição suprema à raça branca. Surgem cientistas, juristas e médicos políticos, pois era necessário unificar o discurso técnico às finalidades que deveriam agradar à sociedade. Houve, portanto, clara deturpação dos argumentos científicos para o atendimento da necessidade dos grupos dominantes.

Percebemos, pois, a contribuição da mídia, da elite intelectual e da academia, por séculos, na criação e manutenção do mito da superioridade da raça branca e, sobretudo, na construção da figura do homem negro perigoso e intelectualmente inferior. Neste sentido, as raízes do Brasil foram regadas a preconceito e discurso de ódio, e vislumbramos suas consequências ainda nos dias atuais.

A isso denomina-se racismo estrutural.

Neste sentido, Sílvio de Almeida (2018) pontua que o racismo pode ser compreendido na percepção individual, na institucional e, por fim, na estrutural. A compreensão individual relaciona racismo com a subjetividade, negando a existência de uma sociedade ou instituições racistas, mas pessoas específicas ou grupos individualizados que o são. Trata-se de uma compreensão limitada e não correspondente com a história, e mesmo com a realidade facilmente perceptível. Já o racismo institucional consiste em um avanço da compreensão do racismo e se relaciona com o Estado, uma vez que admite que temos instituições que atuam de forma distinta a partir do tratamento disponibilizado à diferentes raças. Por tal razão percebemos a ausência de representatividade negra em cargos de direção em empresas públicas e privadas, em setores estratégicos para a sociedade, e mesmo instituições como a polícia - esmagadoramente composta por homens e mulheres negros reproduz o comportamento racista daqueles que detêm o controle do aparto estatal. 
O racismo estrutural corresponderá à relação entre este e a economia, e representa a constatação do racismo arraigado na própria sociedade:

\begin{abstract}
Entretanto, algumas questões ainda persistem. Vimos que as instituições reproduzem as condições para o estabelecimento e a manutenção da ordem social. Desse modo, se é possível falar de um racismo institucional, significa que, de algum modo, a imposição de regras e padrões racistas por parte da instituição é de alguma maneira vinculada à ordem social que ela visa resguardar. Assim como a instituição tem sua atuação condicionada a uma estrutura social previamente existente - com todos os conflitos que lhe são próprios -, o racismo que esta instituição venha a expressar é também parte desta mesma estrutura. As instituições são apenas a materialização de uma estrutura social ou de um modo de socialização que tem o racismo como um de seus componentes orgânicos. Dito de modo mais discreto: as instituições são racistas porque a sociedade é racista (ALMEIDA, 2018, p. 36).
\end{abstract}

Trata-se, portanto, de elemento que compõe o próprio organismo social e, conforme visto anteriormente, especificamente no Brasil, está presente desde a nossa colonização. São séculos e séculos em que somos ensinados que a raça branca é superior às demais e, especificamente, quanto à raça negra, que esta não apenas é cognoscitivamente inferior pois seu crânio se "assemelharia" ao dos primatas - e, por ter a "revolta" dentro de si, atrelada a sua condição de pobreza, seria altamente perigosa.

Em verdade, o que nos foi transmitido, alimentado e reforçado é que o negro ocupa as camadas mais pobres da sociedade em razão da sua inaptidão para o trabalho, quer por sua falta de inteligência, quer porque sua personalidade periculosa tende para a violência, 0 crime; dessa forma, as instituições oficiais do Estado e mesmo as corporações mantêm ao longo do tempo o discurso falacioso da "meritocracia", da liberdade econômica e social, quando, de fato, retira da população negra qualquer chance de ascender financeira e socialmente, pois é desejo das elites que libertaram os escravos a manutenção da posição de subalterno, intelectualmente, financeiramente e culturalmente.

Para tanto, repete-se o enganoso mantra de que todos são igualmente capazes de crescer na sociedade, mas o racismo estrutural que orienta a comunidade faz com que se prefira sempre contratar uma pessoa branca a uma negra; que se prefira ouvir uma pessoa branca a uma negra; pagar uma remuneração maior a uma pessoa branca que a uma negra; compreender os erros da pessoa branca e não os de uma negra. Retiram-se as oportunidades de emprego, de salário justo, acesso a um ensino de qualidade, moradia, lazer, mas se exige que a lei seja duramente aplicada quando há a prática de um delito.

A raça negra é apontada como os inimigos da sociedade, concepção até hoje nutrida, sobretudo com a manutenção e o incremento da criminalização de condutas praticadas por 
pessoas mais pobres, notadamente a imposição de penas mais altas para os crimes contra o patrimônio e o tráfico de drogas.

Neste sentido, a clientela penal é assustadoramente composta por pretos e pardos. De fato, ao analisarmos os dados do DEPEN - Departamento Penitenciário Nacional - de 2019, mais uma vez verificamos que tipos penais mais punidos são os crimes contra o patrimônio, com 50,96 \% (cinquenta vírgula noventa e seis por cento) e drogas, com 20,28\% (vinte vírgula vinte e oito por cento), ou seja, 71,24\% (setenta e um vírgula vinte e quatro por cento) da população carcerária.

Tais delitos são perpetrados, em quase sua totalidade, por pessoas pobres, que, em sua maioria, são negras e pardas. Ou seja: não há como analisar o critério da raça no Brasil dissociado do estudo econômico, o que é fruto do nosso racismo estrutural. Justamente, ao nos debruçarmos sobre os dados quanto à etnia, o levantamento do sistema prisional indica que em 2019 (DEPEN, 2019) tínhamos 49,88\% (quarenta e nove e oitenta e oito por cento) da população prisional parda e 16,81\% (dezesseis e oitenta e um por cento) negra, totalizando 66,69 (sessenta e seis vírgula sessenta e nove por cento) dos encarcerados pretos e pardos.

Por tal razão, o Anuário de Segurança Pública (2019), traz que entre 2017-2018, 75,4\% (setenta e cinco vírgula quatro por cento) das mortes por intervenção policial no Brasil foram de pessoas pretas e pardas.

Destarte, é comum no Brasil negar a existência do próprio racismo, atribuindo-o a outros países, como os Estados Unidos e nações europeias. A própria negação da existência do racismo é o reforço do quão estrutural ele é, do quão enraizado se encontra em nossa sociedade, como leciona Lélia Gonzales:

Ora, na medida em que nós negros estamos na lata de lixo da sociedade brasileira, pois assim o determina a lógica da dominação, caberia uma indagação via psicanálise. E justamente a partir da alternativa proposta por Miller, ou seja: por que o negro é isso que a lógica da dominação tenta (e consegue muitas vezes, nós o sabemos) domesticar? E o risco que assumimos aqui é o do ato de falar com todas as implicações. Exatamente porque temos sido falados, infantilizados (infans, é aquele que não tem fala própria, é a criança que se fala na terceira pessoa, porque falada pelos adultos), que neste trabalho assumimos nossa própria fala. Ou seja, o lixo vai falar, e numa boa.

A primeira coisa que a gente percebe, nesse papo de racismo é que todo mundo acha que é natural. Que negro tem mais é que viver na miséria. Por que? Ora, porque ele tem umas qualidades que não estão com nada: irresponsabilidade, incapacidade intelectual, criancice, etc. e tal. Daí, é natural que seja perseguido pela polícia, pois não gosta de trabalho, sabe? Se não trabalha, é malandro e se é malandro é ladrão. Logo, tem que ser preso, naturalmente. Menor negro só pode ser pivete ou trombadinha (Gonzales, 1979b), pois filho de peixe, peixinho é. Mulher negra, naturalmente, é cozinheira, faxineira, servente, trocadora de ônibus ou prostituta. 
Basta a gente ler jornal, ouvir rádio e ver televisão. Eles não querem nada. Portanto têm mais é que ser favelados.

Racismo? No Brasil? Quem foi que disse? Isso é coisa de americano. Aqui não tem diferença porque todo mundo é brasileiro acima de tudo, graças a Deus. Preto aqui é bem tratado, tem o mesmo direito que a gente tem. Tanto é que, quando se esforça, ele sobe na vida como qualquer um. Conheço um que é médico; educadíssimo, culto, elegante e com umas feições tão finas... Nem parece preto. (1984, p. 225-226)

Não há o que se questionar sobre as origens racistas de nossa sociedade e como o fenômeno está enraizado e as relações dentro das corporações terminam sendo reflexo, como qualquer outra instituição, desse racismo.

Passa-se à análise das políticas de compliance, para, em seguida, abordar sua fundamental contribuição na repressão ao racismo.

\section{As políticas de Compliance}

O Compliance, vocábulo proveniente da língua inglesa "comply" - traduz a ideia de observância e conformidade com o ordenamento. As políticas de compliance, desse modo, corresponderiam a uma série de disciplinas, atos e programas direcionados à incorporação de preceitos éticos, morais, assim como ao entendimento da necessidade de adequação às regras postas. Com essas políticas, delineiam-se as práticas que são desejáveis no ambiente corporativo, bem como aquelas inadmissíveis, dando origem a um sistema de autorregulação regulada, uma vez que as medidas adotadas irão implicar permanente vigilância quanto a sua execução, a fim de coibir o cometimento de condutas ilícitas e irregulares.

Quanto ao seu surgimento, ainda que de forma tímida, remonta ao início do século $\mathrm{XX}$, nos Estados Unidos, durante a denominada década de ouro, momento de produção de leis que uniformizavam as ações de supervisão das indústrias do meio alimentício e farmacêutico (CALIXTO; SIQUEIRA, 2008, p. 99).

Mais tarde, ressurge depois da quebra da bolsa de valores de Nova York, em 1929, no cenário de implantação do programa de recuperação econômica "new deal", objetivando tornar menos rígidos os comandos normativos em vigência, bem como a ação estatal nas organizações financeiras sob o aspecto da ética, individual e coletiva, ocasião em que houve a constituição da organização internacional do Bank for International Settlements (BIS), visando à promoção da cooperação entre instituições bancárias centrais (BERTONI; CARVALHO, 2013, p. 01). 
Na década de 1970, a agência de Securities and Exchange Commission (SEC) deu origem a funções e departamentos de Compliance Officers ao designar sistemas de controle internos, vigilância e fiscalização de atividades suspeitas e capacitação de pessoas (BERTONI, 2012, p. 112).

Com o avançar do tempo, novas acepções, reverberações e utilizações foram agregadas ao signo Compliance, transcendendo esse instituto o lugar no qual se originou, tornando-se transnacional (CARNEIRO, 2018, p.10-25).

Em 1977, nos Estados Unidos, é lançada a Foreing Corrupt Pratices Act (FCPA), lei fundada sobre dois pontos fundamentais: fomentar a transparência no setor contábil das empresas e combater o suborno internacional, coibindo que membros, associados e empregados das companhias americanas subornassem funcionários no exterior em troca de indulgências ou da perpetuação da transação financeira.

Simultaneamente, ainda na década de 1970, foi fundado o Comitê da Basiléia com escopo de proteção aos sistemas financeiros internacionais, que estabeleceu procedimentos de controle sobre as atividades das organizações financeiras (SOBREIRA, 2011, p. 349-376).

Ao final do século $\mathrm{XX}$, o supracitado Comitê Internacional, contando com o Brasil como integrante, procurou promover o equilíbrio das instituições bancárias, estipulando um padrão mínimo de capital às nações participantes e uniformizando a regulamentação cabível às organizações financeiras (TRAPP, CORRAR, 2005 P. 24-36).

O surgimento do Compliance, no Brasil, está estreitamente ligado à liberalização econômica nacional, influenciada, na década de 1990, pelas implicações do Consenso de Washington, momento no qual, no âmbito econômico mundial, conformar-se às normas do mercado de regras e boas práticas tornou-se necessário (FERRARI FILHO, 2008).

Por meio da Lei dos crimes de "lavagem" ou ocultação de bens, a Lei n. 9.613/1998, foi imposto às pessoas físicas e jurídicas destinatárias da norma o dever de utilização de políticas e sistemas de controle internos, bem como se deu origem ao Conselho de Controle de Atividades Financeiras a fim de evitar a prática de "lavagem" de ativos. Por sua vez, a Resolução n. 2.554, de 24.09.1998, exarada pelo Conselho Monetário Nacional, ineditamente, tratou dos "deveres de Compliance".

Deste modo, inspirada pelas ideias do Compliance, o Poder Público lançou mão de práticas para implementar a "Governança Corporativa" no modelo gerencial da 
administração pública já com o princípio da eficiência incorporado à Constituição de 1988 pela Emenda Constitucional 19/1992 (SLOMSKI, 2010, p.933-937).

Na mudança do endurecido modelo burocrático para o sistema gerencial, consoante os apontamentos de Bresser-Pereira (2006, p. 2013), há uma alteração na perspectiva dada às práxis, afasta-se do foco procedimental, colocando em destaque o objetivo e o atendimento ao administrado.

O princípio da eficiência passa a ocupar papel de destaque, torna-se atributo obrigatório não apenas ao poder executivo, mas igualmente a outros poderes, na medida em que pratiquem o papel gerencial, mesmo que de forma atípica (SLOMSKI, 2010, p. 933-937).

Uma nova ordem cultural foi estabelecida, não só quanto à reformulação da administração pública, em razão das demandas internacionais de concessão de crédito e movimentação no mercado financeiro, mas também em virtude da consecução de novos mercados pelo segmento privado, uma vez que a implementação das ideias e práticas de Compliance, no âmbito empresarial, indicam aos consumidores, investidores e parceiros uma boa qualidade (SANTOS, 2012).

A adoção de políticas de Compliance, sob a ótica empresarial, mostra-se como um instrumento de validação da imagem da instituição empresarial no mercado, denotando a conformidade da companhia com as normas e regulações técnicas do âmbito de atuação, bem como, acima de tudo, o seu enquadramento aos valores éticos. Outrossim, a implementação de programas de integridade revela os mediatos resultados de minimização de encargos financeiros e crescimento da confiabilidade da organização.

Ademais, conforme Kitagawa (2009, p. 61-76) preceitua, a introdução do Compliance nas organizações empresariais demanda não só a adequação pelas instituições às normas postas, porém, sobretudo, a análise da eficiência e efetividade da conformidade a essas regras, fato que, com o passar do tempo, atribui credibilidade, sem contar a prevenção das sanções administrativas e judiciais que podem ser impostas pela desconformidade.

A experiência de implantação das políticas de Compliance passa a ser considerada por meio desse prisma, demandando uma nova postura a ser praticada por todos os setores da 
instituição. Há um inconsciente coletivo ${ }^{6}$ que considera que a implementação de políticas de Compliance para uma conformidade com as disposições legais, fiscais e comerciais assegura um retorno social, em razão da adequação ética.

\section{Ética e construção ideológica}

No Brasil, no começo da década de 1990, o Compliance alcançou popularidade, passou-se a compreender, principalmente no setor privado, que, na "era do politicamente correto"7, o instituto, como expressão de conformidade jurídica, poderia ser utilizado como ferramenta para a obtenção de consumidores, justamente por conta desse significante de adequação normativa.

Com o avançar do tempo, a aplicação limitada do Compliance levou à implantação de programas de conformidade sem a necessária compreensão dos protocolos internos das organizações, intrínsecos modos de trabalho, mecanismos aplicados pelas empresas, métodos utilizados pelos recursos humanos e de aprimoramento. De maneira que, considerando a inexistência de fórmula pronta a ser aplicada, especialmente em razão das reivindicações que o mercado vai colocando, no presente momento, a concepção do instituto vem sendo encorpada por novos marcos e abordagens, que colocam novos objetivos e visões das instituições empresariais (CRUZ, 2018, p. 212).

Os motivos para a implantação das políticas de Compliance nas instituições são inúmeros. O Compliance pode ser usado como ferramenta de definição das práticas a serem adotadas para a diminuição das possíveis vulnerabilidades do negócio, bem como para a estruturação de sistema preventivo anticorrupção, aplicável a atividades de qualquer setor, bem como às organizações sem fins lucrativos (SCHRAMM, 2018. p. 317).

\footnotetext{
${ }^{6}$ Válido ressaltar que por inconsciente coletivo deve-se entender, conforme a compreensão de Maffesoli (2006, p. 273-283), embasando-se na concepção junguiana, uma manifestação natural regida por preceitos internos próprios, que se revela em ritmo e tempo particulares, de maneira e fluxo típicos e que aparece e estabelece-se na sociedade.

7 Note-se que, em conformidade com o quanto preceituado por Bauman (2001), a expressão "politicamente correto" é equivalente à de "cultural", uma vez que, sob o aspecto etiológico e histórico, o termo foi retratado nos dicionários como oposto à concepção tida como ciências naturais, isto é, expressando os atributos de uma sociedade, o que ela compreende como valores aceitos e valiosos.
} 
Atos de corrupção, entendidos como condutas contrárias ao quanto estabelecido pelo ordenamento, podem acarretar danos ao prestígio e imagem das instituições, ocasionando perdas monetárias, bem como prejuízos à honra, no aspecto objetivo, da organização, elevando, assim, os gastos de investimento, sem contar com o fato de perpetuarem ações danosas ao desenvolvimento da sociedade.

Levando esses pontos em consideração, revela-se o Compliance como instrumento de implantação de práticas éticas e responsáveis nas instituições, demonstrando que a adoção de condutas preventivas, embasadas, objetivamente, em ações construtivas dos atores dessas organizações, é capaz de frustrar possíveis adversidades da associação, em todos campos (ZYLBERSZTAJN, 2002, p. 21).

É possível entender a ética, de maneira geral e objetivamente considerada, no seu aspecto motivador, como o "estudo dos juízos de apreciação referentes à conduta humana suscetível de qualificação do ponto de vista do bem e do mal, seja relativamente a determinada sociedade, de modo absoluto" (FERREIRA, 2010, p. 2222).

Para Zylbersztajn (2002), pautado nos ensinamentos de Rosansky, a ética pode ser definida como uma tentativa de organização dos comportamentos socialmente aceitáveis e inadequados, a partir de "algum princípio básico", que, no entendimento dessas autoras, se fundamenta nos princípios e ideais do jus naturalismo. Sobre essa questão, as produções literárias indicam que deve ser dada abordagem distinta às questões éticas, relevantes às instituições, e às questões individuais morais. Essa é a posição sobre a qual o presente artigo se ampara.

Considera Marilena Chauí (2000) que agir eticamente demanda a existência de indivíduos com capacidade de discernimento, isto é, um "homem médio", que, indo ao encontro dos pontuados conceitos de inconsciente coletivo e de cultura, estaria apto a compreender o que é adequado ou desacertado, qual conduta é, sob o aspecto moral, rejeitada ou admitida, bem como, até mesmo, aquilo que a sociedade mantém em estado de latência, seja para perpetuar determinados pilares sociais, por razões de preconceito, por interesse ou por outros motivos.

A autora considera que ter uma consciência moral faz com o sujeito seja responsável pela sua forma de atuação, estando ela alinhada ou não com o quanto determinado pela sociedade. A razão e responsabilidade são fundamentais para a vida ética, mesmo que considerada a questão no âmbito íntimo (CHAUÍ, 2000, p. 233). 
Tratando ainda sobre esse ponto, Chauí (2000) assevera que é na capacidade de reflexão, determinação e eleição do comportamento, dentre as inúmeras posturas possíveis de serem adotadas, que se consubstancializa a consciência moral.

No campo do Compliance, a ética possibilita uma criação ideológica nas instituições para a adoção das políticas integrativas, materializada, por exemplo, nos códigos de ética. Em razão das atuais circunstâncias do setor empresarial, a cada dia, os relacionamentos tornam-se mais complexos, fato que demanda constantes atualizações nos programas internos das organizações. Se houver alinhamento entre os códigos de ética e a ação ética do indivíduo, as normas do sistema de integridade ganham relevo e o programa torna-se de relevância comum, coletiva e individualmente (ZYLBERSZTAJN, 2002, p.21).

No âmbito do Direito, há a especificidade de não se lidar apenas com fatos, trabalhando-se também com elementos indiciários e de evidência que podem ser considerados como verdades e, assim, são considerados e externalizados como reais, por meio da coisa julgada. Em outras palavras, tratando-se de normas cogentes, o "dever-ser" é o patamar que se pretende atingir (SOUZA, 2010).

Em razão da particularidade, bem como da extensão, do âmbito jurídico, torna-se mister uma análise mais acurada sobre a relação do instituto do Compliance com o Direito.

Deve ser considerado, conforme pontuado anteriormente, que as atuais e complexas circunstâncias que pesam sobre o setor empresarial, até mesmo em nível internacional, reverberam nas relações jurídicas e de mercado, fato que pode ser levado à apreciação do Poder Judiciário pela esfera cível, administrativa e, até mesmo, penal ${ }^{8}$.

Em razão da era do "politicamente correto", a permanente melhora das políticas das associações se impõe ao âmbito mercantil. É imprescindível que as organizações adotem práticas baseadas na ética, na conformidade com as normas, preocupando-se, claro, com a finalidade dos comandos e com o aperfeiçoamento estratégico (VIEIRA, 2016, p. 477-501).

\footnotetext{
${ }^{8}$ Sobre o âmbito penal, mister a ressalva de que esse campo possui como uma das suas principais fontes as produções doutrinárias que, conforme Luis Greco, funcionam como uma forma de quarto poder, um poder sem moderação, que modera por meio da argumentação (GRECO, 2019, p. 104).
} 
Compliance officer

O Compliance, então, funciona como um instrumento de salvaguarda da imagem das organizações, bem como atestado de qualidade dessas diante no setor na qual se inserem. Para tal fim, no entanto, é necessário que o Compliance Officer esteja em direta conexão com as práticas de governança da corporação e consonante com os valores éticos e de boa atuação empresarial. Como já referido, a adoção de políticas de integridade carrega um objetivo preventivo, que minimizará as vulnerabilidades que afligem as organizações econômicas.

Nas palavras de Renato de Mello Jorge:

Sua estrutura é pensada para incrementar a capacidade comunicativa da pena nas relações econômicas, ao combinar estratégia de defesa da concorrência leal e justa com as estratégias de prevenção de perigos futuros. Ao lado disso, no entanto, também gera novos problemas de atribuição de autoria criminal (MELLO, et. al. 2015, p. 255).

Pode-se compreender que o seu atuar o faz suscetível a tornar-se coautor, ou mesmo partícipe, nos mais variados ilícitos penais, principalmente naqueles contra a ordem econômica, uma vez que consubstancia o ente detentor de todos os dados financeiros e comerciais da associação empresarial, permitindo que a prática de um delito supervisionado por um programa de integridade resulte em investigação e mesmo punição pela via omissiva imprópria (pela função de garantidor assumida) (LEUTERIO, 2014).

A inexistência de normas específicas ocasiona inseguridade jurídica, gerando dúvidas quanto à possibilidade de responsabilização penal de um Compliance Officer em sua atuação ou mesmo quanto a sua omissão no cumprimento de sua obrigação de gerenciamento (COSTA, 2014, p. 215-230).

Ainda que a finalidade do Compliance seja prevenir a prática de atos ilícitos, os programas de integridade influem na determinação da culpabilidade penal, influência que se dá, claro, em etapa posterior ao cometimento da conduta que se almejava frustrar e que pode ser vista no campo da responsabilização tanto dos entes jurídicos, quanto dos físicos (LINHARES, 2015, p. 41-60).

Dessa forma, transpondo a discussão para o tema específico do presente artigo, a prática do racismo ou injúria racial por um dos stakeholders da empresa, pode ocasionar a responsabilização criminal do Compliance Officer por violação ao seu dever de garantidor. 
Tem-se, portanto, mais um argumento para o uso das políticas de conformidade no âmbito preventivo, exigindo-se a fiscalização constante da execução dos programas, a fim de se evitar a prática de ilícitos, notadamente o crime de racismo. É mais vantajoso, sob diversos enfoques, o fomento da cultura do agir correto, cumprindo os preceitos éticos e os regramentos jurídicos. Um desses enfoques, portanto, é justamente o risco de se punir criminalmente não apenas o autor do ilícito em si, mas o Compliance Officer e a alta cúpula da administração da empresa, como garantidores.

\section{As políticas de Compliance na luta antirracista e a necessária mudança cultural}

Passemos à análise da definição de cidadania corporativa, responsabilidade social e as medidas de conformidade a serem adotadas na luta antirracista.

A definição de cidadania corporativa e responsabilidade social

A compreensão de que as políticas de conformidade não exigem somente o atendimento às normas jurídicas, mas a atuação de acordo com os preceitos éticos e morais é terreno para a edificação das principais lutas e conquistas também sociais.

Não mais se admite que uma empresa possua uma visão limitada do que vem a ser lucro. Não se trata do mero somatório de valores financeiros. O patrimônio é composto sobretudo por pessoas: esse é o maior valor a ser protegido e ampliado dentro de uma corporação.

Dessa forma, fomenta-se a construção de uma cidadania corporativa, pois se compreende que a identidade de uma empresa abrange o relacionamento desta com os stakeholders, com a sociedade em geral, as instâncias oficiais do governo e a gestão do meio ambiente. Teremos a convergência entre a responsabilidade social (âmbito econômico, legal, ético e filantrópico) e o desenvolvimento sustentável (meio ambiente). Marcelo Rezende Pinto e José Edson Lara pontuam:

\section{Cidadania corporativa}

Assim como nas discussões sobre responsabilidade social empresarial, não existe unanimidade entre os autores no tocante ao conceito de cidadania corporativa. Segundo Carroll (1998), enquanto alguns autores chamam-na 
responsabilidade social corporativa; outros se referem a ela como ética corporativa. Na visão desse autor, mais recentemente, a performance social dos negócios tem sido chamada de cidadania corporativa. Para Davenport (2000), nos anos de 1990, a cidadania corporativa tornou-se um termo comumente utilizado por profissionais por ser ele o mais indicado para conotar uma série de comportamentos que definem a performance social corporativa. Este termo, conforme Wartick e Cochran (1985), pode ser encarado como qualquer interação entre negócios e ambiente social.

Contudo, Maignan (1999) salienta o fato de que, embora alguns autores considerem cidadania corporativa e performance social corporativa como sinônimos, poderiam ser observadas algumas distinções. Enquanto a performance social corporativa investigaria questões morais, gerenciais e sociológicas, a cidadania corporativa focalizaria atividades mais restritas desenvolvidas pela organização com o escopo de atender a demandas sociais mais concretas.

De qualquer forma, uma integração das diferentes perspectivas conduz aos estudos de Carroll (1991), que propõe uma convergência entre os conceitos de cidadania corporativa e responsabilidade social empresarial, apontando quatro faces para a cidadania corporativa: econômica, legal, ética e filantrópica (2004).

E prosseguem apresentando o seguinte quadro com as definições dos conceitoschave que compõem as quatro dimensões da responsabilidade social empresarial (PINTO, LARA, 2004):

\begin{tabular}{|c|c|}
\hline DIMENSŌES & SIGNIFICADO \\
\hline Econômica & $\begin{array}{l}\text { A dimensão econômica incluiria as obrigações da empresa em ser produtiva, lucrativa e atender às } \\
\text { expectativas dos acionistas de obter retorno sobre o investimento. Todos os outros papéis dos negó- } \\
\text { cios são atributos derivados desse pressuposto fundamental }\end{array}$ \\
\hline Legal & $\begin{array}{l}\text { A dimensão legal requer que o negócio acrescente à sua missão econômica um respeito às leis e aos } \\
\text { regulamentos. A sociedade espera que os negócios ofereçam produtos dentro das normas de seguran- } \\
\text { ça e obedeçam a regulamentações governamentais }\end{array}$ \\
\hline Ética & $\begin{array}{l}\text { A dimensão ética leva em consideração princípios e padrōes que definem a conduta aceitável determi- } \\
\text { nada pelo público, órgãos regulamentadores, grupos privados interessados, concorrentes e a própria } \\
\text { organização. A tomada de decisões deve ser feita considerando-se as conseqūências de suas ações, } \\
\text { honrando o direito dos outros, cumprindo deveres e evitando prejudicar os outros }\end{array}$ \\
\hline Filantrópica & $\begin{array}{l}\text { A dimensão filantrópica prevê que o negócio deve estar envolvido com a melhoria da sociedade por } \\
\text { meio da responsabilidade legal, ética e econômica, bem como a adoção de práticas filantrópicas. } \\
\text { Prevê também atividades que são guiadas pelo desejo dos negócios em se engajar em papéis sociais } \\
\text { não legalmente obrigatórios, mas que estão se tornando cada vez mais estratégicos }\end{array}$ \\
\hline
\end{tabular}

Fonte: Carroll (1991); Carroll (1998); Maignan \& Ferrell (2001a).

Decerto, percebemos que as demandas sociais se encontram não apenas amparadas pela visão moderna de empresa, mas passam a se tornar uma exigência do mercado, 
compondo, inclusive, a estratégia de marketing, pois agregam valor (convertido, inclusive, em valor financeiro) para a pessoa jurídica.

Os consumidores, cada vez mais, primam por produtos e serviços que preservam o meio ambiente, que representam suas convicções éticas, que atuam em conformidade e que tragam representatividade, pois o consumidor está ávido também por apreender produtos de pessoas que espelhem suas próprias condições (em termos de raça, orientação sexual e religiosa). A sociedade vem atravessando a desejada mudança cultural, não mais admitindo empresas envolvidas em escândalos de corrupção, que degradem a natureza, que pratiquem condutas atentatórias à moral e que não respeitem a diversidade.

Neste sentido, recentemente, visualizamos um exemplo concreto sobre o respeito às regas de distanciamento social e ao próximo, em que um casal é flagrado humilhando um agente de fiscalização da Prefeitura do Rio de Janeiro, episódio que ficou conhecido como "cidadão não, engenheiro civil". A empresa para a qual a mulher que apareceu nas reportagens veiculadas pelo país desrespeitando as regras de prevenção e isolamento social e ofendendo o fiscal foi demitida, emitiu a seguinte nota:

A TAESA tomou conhecimento do envolvimento de uma de suas empregadas em um caso de desrespeito às leis que visam reduzir o risco de contágio pelo novo coronavírus e compartilha a indignação da sociedade em relação a este lamentável episódio, sobretudo em um momento no qual o número de casos da doença segue em alta no Brasil e no mundo", consta no comunicado $\left(G_{1}, 2020\right)$.

Trata-se da compreensão da real dimensão do que vem a ser cidadania corporativa. Entretanto, é necessário ir além, tornando-se as políticas de conformidade em importantes ferramentas na luta antirracista.

\section{A luta antirracista}

Dessa forma, o código de ética e conduta da empresa - viga mestra da pessoa jurídica, que abarca a visão, valores e missão do ente coletivo - deve trazer dentre os seus princípios o respeito à diversidade, elencando o preceito étnico racial; deverá ainda trazer como comportamento proibido qualquer conduta racista, passível de punição, inclusive, com demissão por justa causa. 
Há de se inserir no código cláusulas específicas de boas práticas, estabelecendo as condutas exigidas e as proibidas entre os próprios integrantes da pessoa jurídica (sócios, diretores, acionistas, funcionários), entre estes e os fornecedores, terceirizados, consumidores, poder público e a sociedade em geral, bem como as penalidades que podem ser aplicadas diante da infração ao código e às leis. Wagner Giovanini (2014) apresenta, ainda, outros temas relevantes, que devem ser abordados no código de ética, bem como nos treinamentos, cursos e palestras, a fim de embasar a conduta do sócio, funcionário ou parceiro, prevenindo a prática de atos de corrupção, como os conflitos de interesses, presentes e hospitalidades, doações e patrocínios. Com os parâmetros definidos e bem disseminados, a chance da prática de condutas irregulares é drasticamente reduzida. Ou seja: alcança-se a desejada mudança cultural.

Por tal razão, se se está buscando a alteração da adoção de práticas racistas - desde o uso de expressões quotidianas que possuem significado ofensivo, até a percepção da baixa qualidade dos serviços desempenhados pela população negra, fruto de uma construção histórica intencionalmente deturpada, como visto no tópico 01 deste artigo - o código de ética e conduta passa a ser instrumento de grande valia na luta antirracista.

A definição das práticas proibidas e a disseminação de seu conteúdo com todos os stakeholders - devendo se valer de linguagens distintas para alcançar públicos diversos, inclusive, no treinamento dos funcionários, sócios e demais colaboradores sobre o que versa o código - é passo fundamental para se desconstruir velhos conceitos e valores impregnados de preconceito. Ou seja, deve-se disseminar o conteúdo do código, através de cursos, palestras, workshops, distribuições de cartilhas e treinamentos, por exemplo.

Destarte, para que eventuais dúvidas sobre a interpretação das regras do código e das leis gerais, bem como para eventual julgamento de falta funcional, o código de conduta deve ainda estabelecer qual órgão será encarregado da função consultiva e decisória, podendo ser criada uma comissão de ética e conduta, desde que haja a especificação das funções e os integrantes no próprio código.

Além do código de conduta, é desejável que os contratos firmados com funcionários, parceiros, fornecedores, enfim, os stakeholders tragam uma cláusula antirracista, exigindo não apenas do sujeito que irá atuar com a empresa e em nome da empresa um comportamento respeitoso, mas declarando expressamente que o racismo não será 
tolerado, sob pena de aplicação de sanção, que variará desde a imposição de multa, até o encerramento do contrato comercial.

Deve ainda a pessoa jurídica estabelecer ações afirmativas em seu âmago, prevendo a contratação de pessoas negras em seu quadro, com o cuidado, também, de estabelecer critérios para ocupação de cargos de nível hierárquico mais alto, como visualizamos com o exemplo recente da Magazine Luiza ao realizar seleção para trainee exclusiva para pessoas negras (UOL, 2020).

A campanha, que gerou polêmica em todo o território nacional - notadamente em razão do racismo estrutural que permeia a sociedade brasileira - é digna de elogios e deve ser seguida.

Destaca-se que a ação promovida pela empresa teve impacto positivo também na valorização de suas ações, o que condiz com a nova definição de cidadania corporativa e valor da marca da empresa (UNISINOS, 2020). Em pesquisa realizada sobre os impactos financeiros das empresas que instituem ações afirmativas a McKinsey (UOL, 2020) apresentou os seguintes resultados:

Diversidade melhora resultados financeiros, segundo pesquisa.

O que talvez chame mais atenção é que a diversidade impulsiona os resultados financeiros. Um estudo da consultoria McKinsey, feito em diversos países, inclusive o Brasil, mostra que companhias com diversidade cultural e étnica tiveram desempenho financeiro $36 \%$ maior em 2019 que aquelas que não têm tais políticas.

O problema também pode ser visto de forma mais pragmática ao analisar a importância deste público. A maioria da população brasileira é negra, mais especificamente $55,8 \%$ do país, segundo o IBGE -o instituto considera como população que negra a soma entre quem se declara preto $(9,3 \%)$ e pardo $(46,5 \%)$.

Não só é a parcela majoritária no país, como também um grande público consumidor. De acordo com Instituto Locomotiva, este público movimenta $\mathrm{R} \$ 1,7$ trilhão por ano.

As empresas necessitam, ainda, observar a política de remuneração dos colaboradores negros, a fim de corrigir uma injustiça que envolve raça e gênero, como adverte Djamila Ribeiro:

É muito importante perceber que homens negros são vítimas do racismo e, inclusive, estão abaixo das mulheres brancas na pirâmide social. Trazer à tona essas identidades passa a ser uma questão prioritária. Em sua análise, ao não universalizar nem a categoria mulher e nem a homem, Kilomba cumpre esse papel. 
Reconhecer o status de mulheres brancas e homens negros como oscilante nos possibilita enxergar as especificidades desses grupos e romper com a invisibilidade da realidade das mulheres negras. Por exemplo, ainda é muito comum a gente ouvir a seguinte afirmação: "mulheres ganham 30\% a menos do que homens no Brasil", quando a discussão é desigualdade salarial. Essa afirmação está incorreta? Logicamente, não, mas sim do ponto de vista ético.

Explico: mulheres brancas ganham 30\% a menos do que homens brancos. Homens negros ganham menos do que mulheres brancas e mulheres negras ganham menos do que todos. Segundo pesquisa desenvolvida pelo Ministério do Trabalho e Previdência Social em parceria com o Instituto de Pesquisa Econômica Aplicada (IPEA),20 de 2016, 39,6\% das mulheres negras estão inseridas em relações precárias de trabalho, seguidas pelos homens negros $(31,6 \%)$, mulheres brancas $(26,9 \%)$ e homens brancos $(20,6 \%)$. Ainda segundo a pesquisa, mulheres negras eram o maior contingente de pessoas desempregadas e no trabalho doméstico. Essa e outras pesquisas que pensam a partir dos lugares marcados dos grupos sociais conseguem estar mais próximas da realidade e gerar emandas para políticas públicas. Isso porque quando ainda se insiste nessa visão homogênea de homens e mulheres, homens negros e mulheres negras ficam implícitos e acabam não sendo beneficiários de políticas importantes e, estando mais apartados ainda, de serem aqueles que pensam tais políticas (2017, p. 23-24).

Decerto, não basta que a empresa declare que não é racista. É preciso ser antirracista. A contratação de pessoas negras, não apenas para cargos subalternos, mas de gestão, com a equiparação salarial, pagando-se o que é devido pela qualidade técnica e não pelo perfil padrão "desejado" pela sociedade preconceituosa, é essencial nesta luta.

Outrossim, como bem assevera Luciano Knoepke (2019), estar em compliance não pode ser compreendido apenas como seguir as leis internas da empresa e as externas, mas é a cultura de fazer o que é certo, pelo simples fato de ser o certo; as políticas de compliance da empresa serão o farol a guiar toda a atuação da alta administração e funcionários, de todos os colaboradores entre si, com os fornecedores, terceirizados, consumidores e a sociedade em geral. É contemplar e consagrar os valores mais caros à empresa e exigir sua observância.

O comprometimento da alta cúpula da pessoa jurídica é essencial, consagrando a máxima tone from the top, ou seja, o exemplo vem de cima. Ver o exemplo do superior inspira os colaboradores a abraçar os valores trazidos pela empresa, pois se refere à concepção de pertencimento do sujeito à pessoa jurídica, justamente, à noção de identidade.

Neste mesmo sentido, Cheryl Wade (2017) assevera que a diferença entre termos políticas de compliance aparentes (ou, em suas palavras, "cosméticas") e programas efetivos, que de fato trazem um significado, está, justamente, na capacidade dos líderes das empresas 
em inspirar seus colaboradores. Pode-se fazer o mínimo, aquilo que é obrigatório, e se pode obter maiores resultados com a incorporação na identidade das empresas de tais valores. (WADE, 2017, p. 1191-1192).

Dessa forma, somente teremos a desejada e necessária mudança, com a desarticulação do racismo estrutural que é refletido e se espraia nas raízes das corporações, quando as decisões forem tomadas por pessoas não brancas, pois de nada adianta que pessoas caucasianas digam quais são as ações que irão beneficiar as pessoas negras e pardas (WADE, 2017, p. 1201). É preciso que essas pessoas ocupem o lugar de decisão, que lhe seja assegurado o lugar de fala9 que lhe pertence.

Por tal razão, as políticas de integridade apresentam-se como importante ferramenta para esta conquista.

\section{Considerações finais}

Percebemos como o racismo encontra-se arraigado na estrutura de nossa sociedade; as corporações, por sua vez, ao espelharem os interesses daqueles que a dirigem e a representam, terminam por reproduzir e reforçar o racismo estrutural.

Dessa forma, as políticas de compliance, que se referem ao atuar em conformidade, observando o regramento legal e os preceitos éticos e morais, terminam por serem importantes ferramentas para a luta antirracista.

Malgrado os programas de conformidade tenham sido edificados numa perspectiva econômica, mais voltada ao combate aos crimes financeiros e à corrupção, suas diretrizes se revelam muito mais amplas e profundas, exigindo de todos os stakeholders da empresa que atuem segundo as leis e a ética. Desafia-se, portanto, que todos os envolvidos com o ente coletivo respeitem os direitos fundamentais e a prática não discriminatória se encontra dentre eles.

\footnotetext{
${ }^{9} \mathrm{Na}$ perspectiva não apenas de que todas as vozes devem ser ouvidas, mas, notadamente, na compreensão de que o sujeito deve ter lucidez sobre seu papel nas lutas sociais, perceber se é protagonista ou coadjuvante, bem como por que ocupa determinado papel. É a necessária tomada de consciência da pessoa e do corpo social e a garantia do respeito ao que a pessoa necessita transmitir, sem silenciar ou invisibilizar parcelas da população. (Cf. RIBEIRO, 2017).
} 
Entretanto, para que haja uma verdadeira mudança cultural, rompendo com as correntes do racismo estrutural, há de se construir um programa de conformidade efetivo, numa perspectiva antirracista: desde o código de ética e conduta trazendo a proibição da prática de ações/omissões racistas, perpassando pela inserção de cláusulas antirracistas nos contratos celebrados com os colaboradores e mesmo no contrato social envolvendo a alta cúpula da pessoa jurídica, até a política de contratação de pessoas negras, com equiparação salarial e ocupando cargos de chefia e direção, pois somente assim teremos, propriamente, programas capazes de alcançar a desejada mudança cultural.

\section{Referências}

ALMEIDA, Sílvio Luiz de. O que é racismo estrutural. Belo Horizonte: Letramento, 2018.

AZEVEDO, Célia Maria Marinho de. Onda negra medo branco: o negro no imaginário das elites do século XIX. Rio de Janeiro: Paz e Terra, 1987.

BATISTA, Nilo. Concurso de agentes: uma investigação sobre os problemas da autoria e da participação no Direito Penal Brasileiro. 3 ed. Rio de Janeiro: Lumen Juris, 2005, p. 134.

BAUMAN, Zygmunt. Modernidade Líquida. Tradução: Plínio Dentzien. Jorge Zahar Editor, 2001. $258 \mathrm{p}$.

BERTONI, Felipe Faoro. O delito de lavagem de capitais e o desenvolvimento do criminal compliance. Revista Jurídica Eletrônica da UFPI, [S.I.], v. 1, n. 03, 2012.

BERTONI, Felipe Faoro; CARVALHO, Diogo. Criminal Compliance e lavagem de dinheiro. Disponível em: https://ebooks.pucrs.br/edipucrs/anais/cienciascriminais/IV/o8.pdf. Acesso em: 22 jun. 2019, 2013.

BRESSER-PEREIRA, Luiz Carlos. Estratégia nacional e desenvolvimento. Rev. Econ. Polit., São Paulo, v. 26, n. 2, p. 203-230, jun., 2006. Disponível em:

$<$ http://www.scielo.br/scielo.php?script=sci_arttext\&pid=S0101-

31572006000200003\&lng=en\&nrm=iso>. Acesso em: 14 abr. 2019. Doi:

https://doi.org/10.1590/S0101-31572006000200003.

CALIXTO, J. B.; SIQUEIRA JÚNIOR J. M. Desenvolvimento de Medicamentos no Brasil: Desafios.

Gazeta Médica da Bahia, Salvador-Bahia, v. 78, suplemento 1, p. 98-106, 2008.

CARNEIRO, Cláudio. A era do Compliance em tempo de globalização e (neo) constitucionalismo. Direito, globalização e transnacionalidade. PIFE, Carla; OLIVEIRA NETO, Francisco José R. de; LOCAl, Maria Chiara (org). Principiologia constitucional

e política do Direito. Itajaí: UNIVALI, 2018. t.4: Direito, globalização e transnacionalidade, p. 10-24. Disponível em: http://www.univali.br/ppcj/ebook. Acesso em: 01 mar 2021. 
CHAUÍ, Marilena. Convite à Filosofia. Ed. Ática, São Paulo, 2000. Disponível em: http://www.projeto.unisinos.br/humanismo/etica/constituinteseticos.pdf. Acessado em o3/07/2019

COSTA, Helena Regina Lobo da, Marina Pinhão Coelho Araújo. Compliance e o Julgamento da APn 470. Revista Brasileira de Ciências Criminais, São Paulo: n. 106, p. 215-230, jan./fev. 2014.

CRUZ, R. F.A. Controle interno \& governança pública: um estudo no Governo do Estado de Minas Gerais. 2018. Dissertação (Mestrado Profissional em Administração). Fundação Cultural Dr. Pedro Leopoldo - FPL, Pedro Leopoldo, 2018. Disponível em: https://www.fpl.edu.br/2018/media/pdfs/mestrado/dissertacoes 2018/dissertac ao_rodrigo_fischer_cruz_2018.pdf Acesso em: 13 jan. 2021.

DEPEN. Levantamento nacional. [S.I., (2021?)], Disponível:

http://antigo.depen.gov.br/DEPEN/depen/sisdepen/infopen Acesso em: 01 mar. 2021.

FERRARI FILHO, Fernando. Globalização, Estado e Desenvolvimento: dilemas do Brasil no novo milênio. Rev. Econ. Polit, São Paulo, v.28, n. 2, abr./jun. 2008. Disponível em:

http://www.scielo.br/scielo.php?script=sci_arttext\&pid =S0101-31572008000200 011. Acesso em: 02 jul. 2019

FERREIRA, Aurélio Buarque de Holanda. Dicionário da língua portuguesa. 5. ed. Curitiba: Positivo, 2010. 2222 p. ISBN 978-85-385-4198-1.

FÓRUM DE SEGURANÇA PÚBLICA. Anuário Brasileiro de Segurança Pública. [S.I.], 2019. Disponível em: < https://www.forumseguranca.org.br/wp-content/uploads/2019/10/Anuario-2019FINAL_21.10.19.pdf> Acesso em: 03 mar. 2021

G1 RIO DE JANEIRO. Mulher que discutiu com fiscal e disse que marido era melhor por ser 'engenheiro civil' é demitida. Rio de Janeiro, 2020. Disponível em: <https://g1.globo.com/rj/rio-dejaneiro/noticia/2020/07/06/mulher-flagrada-humilhando-fiscal-em-reportagem-do-fantastico-edemitida.ghtml> Acesso em: 13 set. 2020.

GIOVANNI, Wagner. Compliance, a excelência na prática. São Paulo: editora própria, 2014.

GRECO, Luís. Dogmática e Ciência do Direito Penal. In. VIANA, Eduardo et. al (trad. org.). As razões do direito penal. Quadro Estudos. São Paulo: Marcial Pons, 2019. 104 p.

GONZALES, Lélia. Racismo e sexismo na cultura brasileira. In: Revista Ciências Sociais Hoje (Anpocs), [s.l.], p. 223-244, 1984.

GOULD, Stephen Jay. A falsa medida do homem. São Paulo: Martins Fontes, 1991.

IBGC. Compliance à luz da Governança Corporativa. [S.I., (2021?)]Disponível em: https://www.legiscompliance.com.br/images/pdf/ibgc_orienta_compliance_a_luz da_governaca.pd f Acesso em 01 mar. 2021.

INSTITUTO HUMANITAS UNISINOS. Ações da Magazine Luiza sobem após anúncio de vagas de trainees só para negros. São Leopoldo, 25 set. 2020. Disponível em: http://www.ihu.unisinos.br/78noticias/603176-acoes-da-magazin-luiza-sobem-apos-anuncio-de-vagas-de-trainees-so-paranegros Acesso em: 01 mar. 2021. 
KITAGAWA, Carlos Henrique; RIBEIRO, Maísa de Souza. Governança corporativa na América Latina: a relevância dos princípios da OCDE na integridade dos conselhos e autonomia dos conselheiros.

Rev. contab. finanç. [online], [s.I.], v.20, n.51, p.61-76, 2009. DOI: http://dx.doi.org/10.1590/S151970772009000300005 . Acessado em 30 jun. 2019

KNOEPKE, Luciano. O sistema de compliance: notas introdutórias. In: Revista Jurídica da Escola Superior de Advocacia da OAB-PR, [s.I.], a. 4, n. 2, p. 78, out. 2019.

LEUTERIO, Alex Pereira. Criminal Compliance e o pensamento penal de Silva-Sanchez. [S.I., (2019?)]. Disponível em: http://www.conteudojuridico.com.br/consulta/Artigos/39331/criminalcompliance-e-o-pensamento-penal-de-silva-sanchez\#_ftnref22 Acesso em: 19 jun. 2019.

LINHARES, Sólon Cicero; OLIVEIRA, Daniele Aparecida de. O conceito construtivista de culpabilidade e a responsabilidade penal das pessoas jurídicas por crimes ambientais. Uma análise através da figura do compliance. Revista Jurídica - FURB, [s.I.], v. 19, n. 40, p. 41 - 6o, set./dez. 2015. https://proxy.furb.br/ojs/index.php/juridica/article/view/4960 Acesso em: 04 fev. 2020

MAFFESOLI, Michel. Comunidade de destino. Horiz. antropol., Porto Alegre, v. 12, n. 25, p. 273283, Jun. 2006. Disponível em: http://www.scielo.br/scielo.php ?script=sci_arttext\&pid=S010471832006000100014\&lng=en\&nrm=iso. accesso em: 14 jun. 2019. DOI: http://dx.doi.org/10.1590/S0104-71832006000100014.

MENDONÇA, Suellen de Carvalho et al. Sistema de formação do conhecimento e da inteligência em uma empresa farmacêutica nacional e sua interação com o setor de Assuntos Regulatórios. 2016. 143 f. Dissertação (Mestrado em Gestão, Pesquisa e Desenvolvimento na Indústria Farmacêutica) - Instituto de Tecnologia em Fármacos/Farmanguinhos, Rio de Janeiro, 2016. Dsiponível em: https://www.arca.fiocruz.br/handle/icict/17731. Acesso em 01 mar. 2021.

PINTO, Marcelo de Rezende; LARA, José Edson. A cidadania corporativa como uma orientação de marketing: um estudo no varejo. Revista de Administração de Empresas [online].[s.I.], v. 44, n. spe, p. 48-6o, 2004. Disponível em: <https://doi.org/10.1590/S0034-75902004000500004>. Acesso em: 01 mar. 2021.

RIBEIRO, Djamila. O que é lugar de fala? Belo Horizonte: Letramento, 2017.

RODRIGUES, Raymundo Nina. As raças humanas e a responsabilidade penal no Brasil. Rio de Janeiro: Revan, 2011.

SANTOS, Renato Almeida dos et al. Compliance and leadership: the susceptibility of leaders to the risk of corruption in organizations. Einstein [online], São Paulo, v. 10, n. 1, p. 1-10, 2012. DOI:. https://doi.org/10.1590/S1679-45082012000100003.

SCHRAMM, F. S. O Compliance como Instrumento de Combate à Corrupção no Âmbito das Contratações Públicas. 2018. 317 p. Dissertação (Mestrado em Direito). Universidade Federal de Santa Catarina, Florianópolis, 2018. Disponível em: https://edisciplinas.usp.br/mod/resource/ view.php?id=2311080. Acesso em: 20 jun. 2019.

SIEBER, Ulrich. Programas de Compliance no Direito Penal Empresarial: um novo conceito para o controle da criminalidade econômica. In: OLIVEIRA, Willian T.; ESSADO, Tiago C.; LEITE NETO, Pedro Ferreira; SAAD-DINIZ, Eduardo. Direito Penal Econômico: estudos em homenagem aos 75 anos do professor Klaus Tiedemann. São Paulo: Liber Ars, 2013. 
SLOMSKI, Valmor et al. A demonstração do resultado econômico e sistemas de custeamento como instrumentos de evidenciação do cumprimento do princípio constitucional da eficiência, produção de governança e accountability no setor público: uma aplicação na Procuradoria-Geral do Município de São Paulo. Rev. Adm. Pública, [s.l.], v.44, n. 4, p.933-937, ago. 2010. Disponível em: <http://www.scielo.br/pdf/rap/v44n4/v44n4ao8.pdf>. Acesso em: 20 jun. 2019.

SOBREIRA, R., \& Martins, N. M. Os Acordos de Basileia e bancos de desenvolvimento no Brasil: uma avaliação do BNDES e do BNB. Revista de Administração Pública - RAP, [S.I.], v.45, n. 2, p. 349376, 2011. - Disponível em: http://www.scielo .br/scielo.php?script=sci_nlinks\&ref=000270\&pid=S1519-7077201300030000300055 \&lng=pt. Acesso em: 20 jun. 2019.

SOUZA, Marcus V. S. Guimarães de. O Direito como Ciência. [S.I. (2017?)]. Disponível em: https: //valeriosaavedra.jusbrasil.com.br/noticias/2667165/o-direito-como-ciencia. Acesso em 13 abr. 2017.

SCHWARZ, Lila. Espetáculo da miscigenação. Estudos avançados. [online], [s.I.], v..8, n.20, p.137152, 1994 .

TRAPP, Adriana Cristina Garcia; CORRAR, Luiz J. Avaliação e gerenciamento do risco operacional no Brasil: análise de caso de uma instituição financeira de grande porte. Rev. contab. finanç., São Paulo, v. 16, n. 37, p. 24-36, apr. 2005. Available from $<$ http://www.scielo.br/scielo.php?script=sci_arttext\&pid=S151970772005000100002\&lng=en\&nrm=iso >. access on 15 Feb. 2021.http://dx.doi.org/10.1590/S151970772005000100002 .

UOL. Empresas contra o racismo. Disponível em: <https://economia.vol.com.br/reportagensespeciais/como-empresas-podem-ser-antirracistas/index.htm\#cover> Acesso em: 01 mar. 2021.

UOL ECONOMIA. 'É inaceitável termos só $16 \%$ de líderes negros' diz CEO da Magalu. Disponível em: <https://economia.vol.com.br/noticias/estadao-conteudo/2020/og/21/e-inaceitavel-termos-so16-de-lideres-negros-diz-frederico-trajano.htm> Acesso em 01 mar. 2021.

VIEIRA, Valter Afonso. Incentivos Extracontratuais e Comportamentos Ex Post no Relacionamento entre Shopping e Lojista. Rev. adm. contemp., Curitiba, v. 20, n. 4, p. 477-501, ago. 2016. Disponivel em http://www.scielo.br/scielo.php?script=sci arttext\&pid=S1415$65552016000400477 \&$ lng=pt\&nrm=iso. Acesso em: 15 fev. 2021. Disponível em: http://dx.doi.org/10.1590/1982-7849rac2016150013.

ZYLBERSZTAJN, Decio. Organização ética: um ensaio sobre comportamento e estrutura das organizações. Rev. adm. contemp., Curitiba, v. 6, n. 2, p. 123-143, aug. 2002. Available from http://www.scielo.br/scielo.php? script=sci_arttext\&pid $=\mathrm{S}_{1415-}$ 65552002000200008\&lng=en\&nrm=iso. Access on: 13 mar. 2017.

WADE, Cheryl. Effective Compliance with Antidiscrimination Law: CorporatePersonhood, Purpose and Social Responsibility. Disponible in:

<https://scholarlycommons.law.wlu.edu/wlulr/vol74/iss2/22/ > Access: 01. March 2021.

\section{Detalhes dos autores}

Fernanda Ravazzano Lopes Baqueiro 
Phd em Relações Internacionais pela Universitat de Barcelona (Espanha). Profa. do Mestrado e Doutorado em Políticas Sociais e Cidadania - UCSal. E-mail: fravazzano@gmail.com.

\section{Silvia Monique Santos Cezar}

Mestre em Direito pela UCSal, Membro do grupo de pesquisa Criminologia Crítica na América Latina: punitivismo, políticas sociais equivocadas e violação aos Direitos Humanos da Ucsal. 